DOE-SPEC-3021-97

April 1997

\title{
DOE SPECIFICATION
}

\section{UNINTERRUPTIBLE POWER SUPPLY (UPS) SYSTEMS}

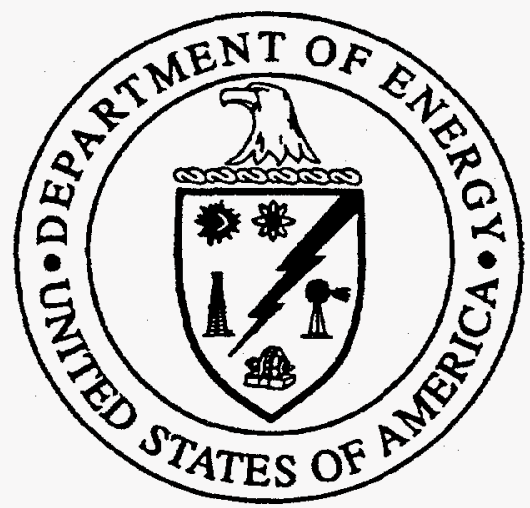

U.S. Department of Energy 
This document has been reproduced directly from the best available copy.

Available to DOE and DOE contractors from the Office of Scientific and Technical Information, P.O. Box 62, Oak Ridge, TN 37831; (423) 576-8401.

Available to the public from the U.S. Department of Commerce, Technology Administration, National Technical Information Service, Springfield, VA 22161; (703) $487-4650$.

Order No. DE97007453 


\section{DISCLAMMER}

Portions of this docament may be illegible in electronic image products. Images are produced from the best available original document. 


\section{DOE-SPEC-3021-97}

\section{FOREWORD}

1. Use of this purchase specification is not mandatory. User should review the document and determine if it meets the user's purpose.

2. Comments (recommendations, additions, and deletions) and any pertinent data that may be of use in improving this document should be addressed to: DOE Backup Power Working Group, c/o John Fredlund, DP-45/GTN, U.S. Department of Energy, 19901 Germantown Road, Germantown, MD 20874-1290.

3. This document contains a "fill-in-the-blanks" guide specification for the procurement of uninterruptible power supply (UPS) systems greater than $10 \mathrm{kVA}$, organized as follows:

- Parts 1 through 7: Technical requirements.

- Appendix A:

Technical requirements to be included in the proposal.

- Appendix B:

UPS system data sheets to be completed by each bidder (Seller) and submitted with the proposal.

- Appendix C General guidelines giving the specifier parameters for selecting a UPS system. It should be read before preparing an actual specification, and is not attached to the specification.

- Attachment 1: Sketches prepared by the purchaser (Owner).

- Attachment 2: Sample title page.

4. Because this guide specification contains blanks for the specifier to enter quantities, both metric and inch-pound units have been noted where appropriate, with the metric unit in parentheses. Select one system or the other (not both) when using the specification.

5. This document was produced by DOE's Backup Power Working Group for the use of its members. This group is making this document available for the benefit of others through the DOE Technical Standards Program. Other similar products are available and may be obtained from our web site, currently at http://www3.dp.doe.gov/CTG/bpwg/bpwg.htm. 


\section{DOE-SPEC-3021-97}

6. Most of the guide specification is "boilerplate;" i.e., it will always remain the same from job to job. The portions of the specification that are job specific are highlighted for the specifier's attention in one of the following ways:

\section{FLAG}

ATTENTION:

[item]

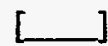

\section{MEANING}

These are explanatory notes that precede areas in the text requiring editing. The nature of the choice and the type of action (or research) required is explained in the note.

These are action items within the text of the specification. If the bracketed item is by itself, it is an optional requirement that may or may not be specified according to circumstances. If there are a pair of bracketed items, or a series of them, they represent alternate choices that may be made in accordance with varying circumstances; one (or more) of them must be chosen by the specifier.

A blank in the text means that the specifier must supply a specific value, text, or dimension. Blanks in the text are generally preceded by ATTENTION: notes that explain the nature of the value or dimension that must be supplied.

7. After the specifier has finished supplying all the requested information in the guide specification, a word processor can incorporate all the choices made and delete all the ATTENTION: notes. What remains will be the finished specification that may be used as a bid document.

8. Appendices $A$ and $B$, and Attachment 1 are to be used by each bidder as a guide for preparing the technical proposal.

9. Please note that this specification assumes the storage battery will be separately specified. DOE-SPEC-3018-96 or DOE-SPEC-3019-96 are perfectly suited for this use. 


\section{CONTENTS}

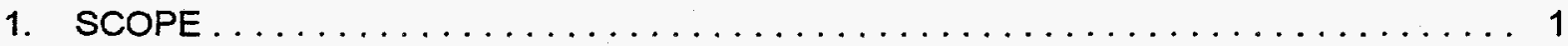

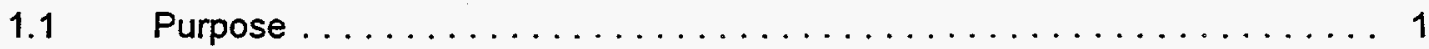

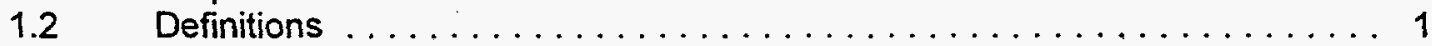

$1.3 \quad$ Work to be provided $\ldots \ldots \ldots \ldots \ldots \ldots \ldots \ldots \ldots \ldots \ldots$

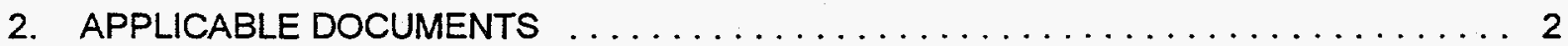

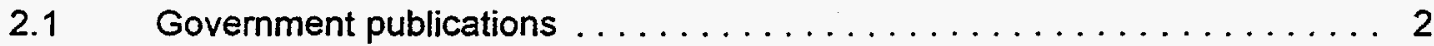

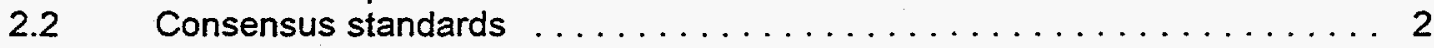

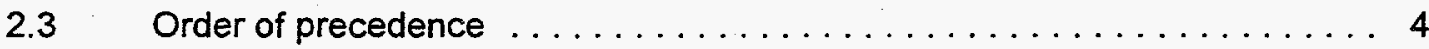

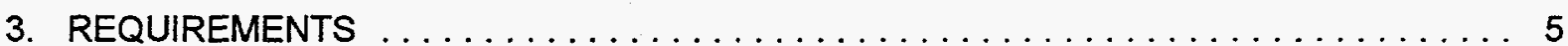

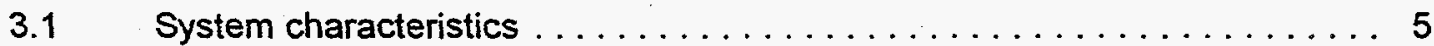

3.2 Source characteristics . . . . . . . . . . . . . . . . . . 6

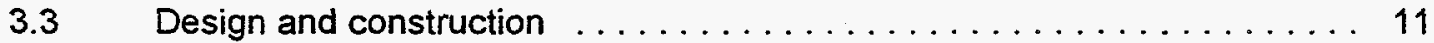

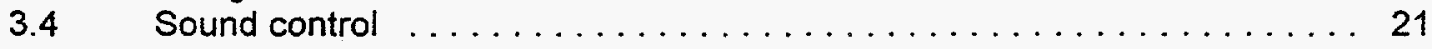

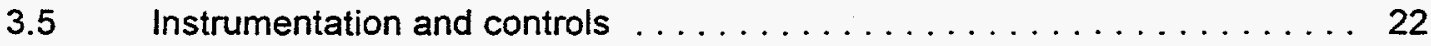

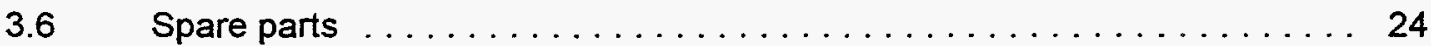

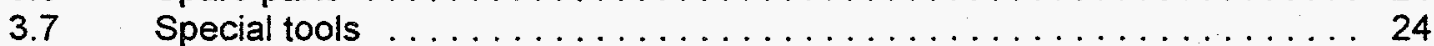

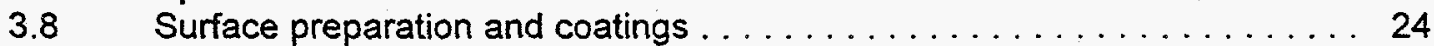

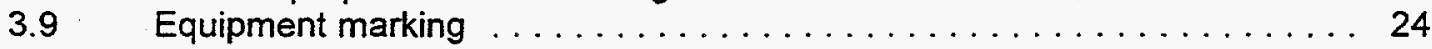

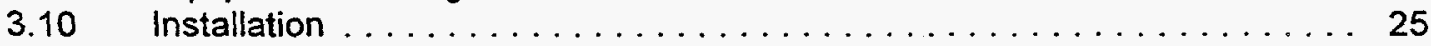

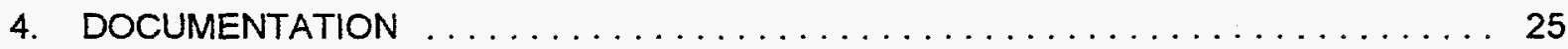

$4.1 \quad$ General . . . . . . . . . . . . . . . . . . . . . . . . 25

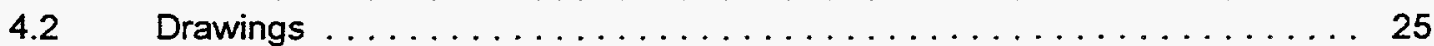

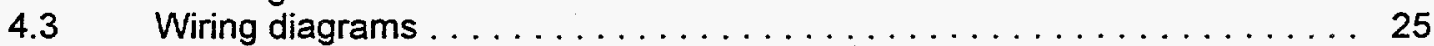

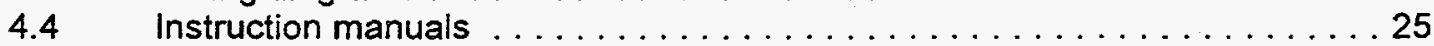

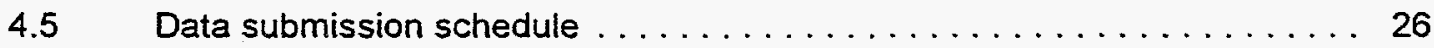

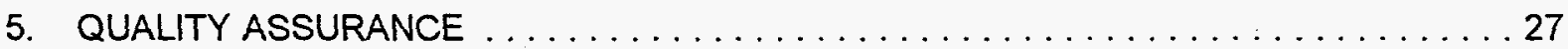

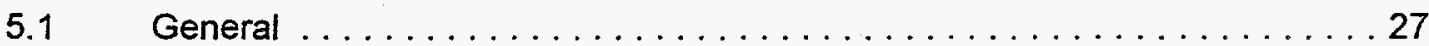

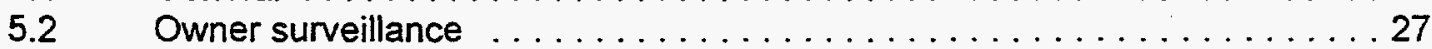

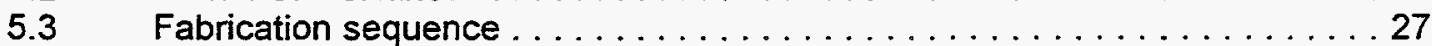

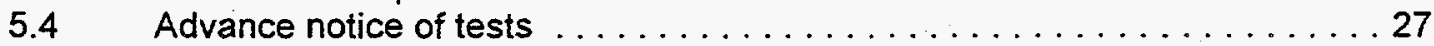

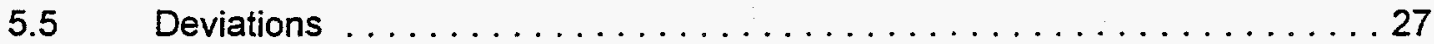

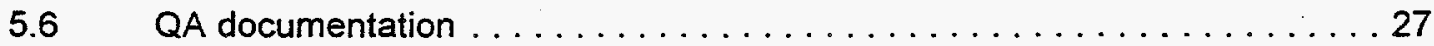

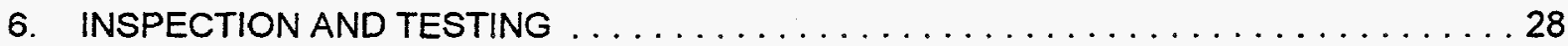

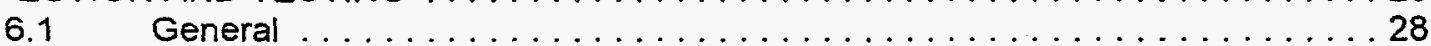

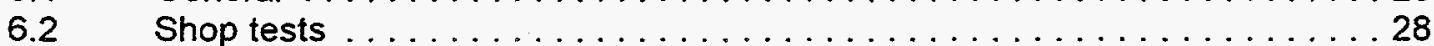

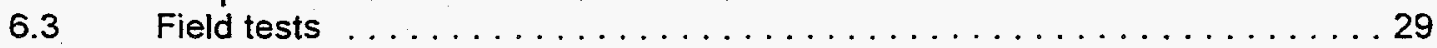




\section{DOE-SPEC-3021-97}

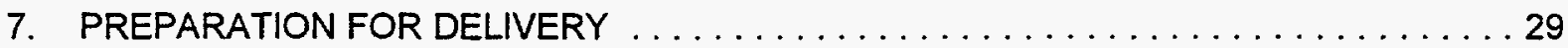

7.1

7.2

7.3

Cleaning

29

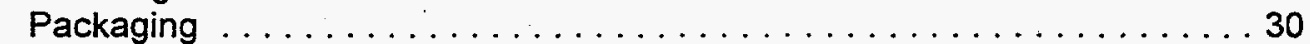

Labeling . . . . . . . . . . . . . . . . . . . . . . . 30

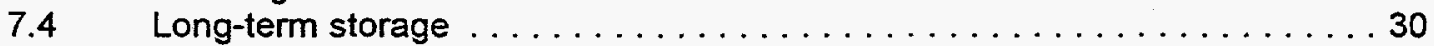

APPENDICES

A ADDITIONAL TECHNICAL REQUIREMENTS $\ldots \ldots \ldots \ldots \ldots \ldots \ldots$ A-1

B UPS SYSTEM DATA SHEETS $\ldots \ldots \ldots \ldots \ldots \ldots \ldots \ldots \ldots \ldots \ldots \ldots \ldots$ B-1

C GENERAL GUIDELINES FOR UPS SELECTION $\ldots \ldots \ldots \ldots \ldots \ldots \ldots \ldots$ C-1

ATTACHMENTS

1 SKETCHES

2 TITLE PAGE (sample) 
1. SCOPE

ATTENTION:

Self-contained UPS systems of the desktop or rack-mount type with sealed maintenancefree batteries should not be procured with this specification due to their unique requirements. Provide the name and location of the facility.

1.1 Purpose. This specification defines requirements for the design, manufacture, testing and delivery of an uninterruptible power supply (UPS) system for [ ], located in

$$
\text { ]. Owner's facility }
$$

City, State

ATTENTION:

Define the following terms as used at this facility, to avoid confusion.

two

1.2 Definitions.

\subsubsection{Owner. [}

\subsubsection{Seller. [}

1.3 Work to be provided. Seller shall provide the following:

a. Design, manufacture, shop test, and provide a complete UPS system, including any accessory equipment for use in operation or maintenance of the system.

b. Provide certification that the UPS system has been approved by a nationally recognized testing laboratory (NRTL) recognized under 29 CFR 1910.7.

c. Deliver all equipment. Provide packaging for equipment protection during transportation and storage.

d. Provide all data and information required for storage, installation, startup, operation and maintenance.

e. Provide technical and startup advice and assistance as the Owner requires.

\section{ATTENTION:}

Include the following reference if a battery system is being provided and is specified separately.

th

f. Provide a storage battery, battery [rack] [cabinet], and accessories in accordance with attached [Specification ] 


\section{APPLICABLE DOCUMENTS}

The following documents form part of this specification to the extent stated herein. Unless otherwise indicated, use the issue in effect on the date of request for quotation. Bring any conflicts between this specification and referenced documents to the Owner's attention in writing for resolution before taking any related action. Where differences exist between codes and standards, the one affording the greatest protection shall apply.

\subsection{Government publications.}

Code of Federal Regulations (CFR)

29 CFR $1910 \quad$ Occupational Safety and Health Standards (Fed/OSHA)

29 CFR 1910.7 Definitions and Requirements for a Nationally Recognized Testing Laboratory (NRTL)

29 CFR $1910.95 \quad$ Occupational Noise Exposure

(Copies of the above documents are available from the Superintendent of Documents,

U.S. Government Printing Office, Washington, DC 20402.)

\section{U. S. Department of Energy}

DOE-SPEC-3018-96 Flooded-Type Lead-Acid Storage Batteries

DOE-SPEC-3019-96 Valve-regulated Type Lead-Acid Storage Batteries

(Copies of the above documents are available to DOE and DOE contractors from the Office of Scientific and Technical Information, P. O. Box 62, Oak Ridge, TN 37831; (423)576-8401; http://apollo.osti.gov/html/techstds/techstds.html.)

\subsection{Consensus standards.}

\section{American Institute of Steel Construction (A/SC)}

AISC Applicable Standards

\section{American National Standards Institute (ANSI)}

ANSI C39.1 Electrical Analog Indicating Instruments

ANSI C89.1 Transformers

Institute of Electrical and Electronics Engineers, Inc. (IEEE)

IEEE 100

Dictionary of Electrical and Electronics Terms

IEEE 446

IEEE Recommended Practice for Emergency and Standby Power Systems for Industrial and Commercial Applications 
DOE-SPEC-3021-97

IEEE 519

IEEE 944

IEEE C37.90

IEEE C37.90.1

IEEE C62.41
IEEE Guide for Harmonic Control and Reactive Compensation of Static Power Converters

IEEE Recommended Practice for the Application and Testing of Uninterruptible Power Supplies for Power Generating Stations

Relays and Relay Systems Associated with Electric Power Apparatus

Guide for Surge Withstand Capability (SWC) Tests

IEEE Guide for Surge Voltages in Low-Voltage AC Circuits

Insulated Cable Engineers Association (ICEA)

ICEA S-66-524 Cross-Linked-Thermosetting Polyethylene-Insulated Wire and Cable for the Transmission and Distribution of Electric Energy

International Conference of Building Officials (ICBO)

ICBO UBC Uniform Building Code

National Electrical Manufacturers Association (NEMA)

NEMA ICS 2 Standards for Industrial Control Devices, Controllers, and Assemblies

NEMA ICS $6 \quad$ Enclosures for Industrial Controls and Systems

NEMA PE $1 \quad$ Uninterruptible Power Systems

NEMA PE $5 \quad$ Constant Potential Type Electric Utility (Semi-conductor Static Converter) Battery Chargers

\section{National Fire Protection Association (NFPA)}

NFPA 70

National Electrical Code

Art. 480 Storage Batteries

NFPA 111

Stored Electrical Energy Emergency and Standby Power Systems

Steel Structures Painting Council (SSPC)

SSPC PA $1 \quad$ Shop, Field, and Maintenance Painting

Underwriters Laboratories, Inc. (UL)

UL 44

Rubber Insulated Wire and Cable 


\section{DOE-SPEC-3021-97}

UL 1561

Dry-Type Transformers

UL 1778

Uninterruptible Power Systems

(Copies of non-government publications are normally available from the organizations that prepare or distribute the documents. These documents may also be available in or through libraries or other informational services.)

AISC:

American Institute of Steel Construction, Inc.; 1-800-644-2400

The Wrigley Building

400 N. Michigan Avenue

Chicago, IL 60611

ANSI:

American National Standards Institute; $212-642-4900$

11 West 42nd Street

New York, NY 10036

IEEE: Institute of Electrical and Electronics Engineers; 800-678-IEEE 445 Hoes Lane, P.O. Box 1331

Piscataway, NJ 08855-1331

IGEA: $\quad$ Insulated Cable Engineers Association; 508-394-4424

P.O. Box 440

South Yarmouth, MA 02664

ICBO: International Conference of Building Officials; (562)699-0541

5360 Workman Mill Road

Whittier, CA 90601-2298

NEMA: $\quad$ National Electrical Manufacturers Association ; (703) 841-3200 2101 L Street NW

Washington, DC 20037

NFPA: $\quad$ National Fire Protection Association (617); 770-3000

One Batterymarch Park, P.O. Box 9101

Quincy, MA 02269-9101

SSPC: $\quad$ Steel Structures Painting Council; (412) 281-2331

40 24th Street

Pittsburgh, PA 15222

UL: $\quad$ Underwriters Laboratories, Inc.; 847-272-8800

333 Pfingsten Road

Northbrook, IL 60062

2.3 Order of precedence. In the event of conflict between the text of this document and the references cited herein, the text of this document takes precedence. Nothing in this 
document, however, supersedes applicable laws and regulations unless a specified exemption has been obtained.

\section{REQUIREMENTS}

\subsection{System characteristics.}

3.1.1 General. The UPS system will supply power to an ac bus that supplies loads, such as computers, controls, fire protection, alarms, communication equipment, and recorders, that cannot tolerate even a momentary loss of ac power. The UPS system shall have the following characteristics:

UPS Inverter Continuous Output Rating @ 1.0 to 0.8 power factor $(\mathrm{pf}$ ) lagging at site maximum ambient and site elevation kVA

Output $A C$ Voltage

Output Phase/Wire

Ground

[S-Solid] [U-Ungrd'd]

Output Frequency $\mathrm{Hz}$

Bypass Transformer Reqd. [Yes] [No]

Constant Voltage Regulating Bypass Transformer Reqd.

[Yes] [No]

UPS Module Efficiency:

$\angle O A D$

(\% of normal)

25

50

100
MINIMUM EFFICIENCY

ATTENTION:

Enter the number of years of required design life below.

3.1.2 Design life. The design life shall be $L]$ years.

ATTENTION:

Enter the required mean time between failures (MTBF) below.

3.1.3 Mean time between failures (MTBF). The design MTBF shall be [] hours 


\subsection{Source characteristics.}

ATTENTION:

Enter the characteristics of the normal input source below. If the input may come from more than one source (such as commercial power or standby generator), then enter the worst case parameters. Remember the available short circuit current depends on the upstream protection circuits. The normal voltage and frequency variations of most commercial power systems is $\pm 5 \%$ and $\pm 0.5 \%$ respectively.

A complete input source specification should also include any transients expected on the system. Two common conditions are listed, but the responsible engineer must know the source to be used and then list any additional conditions that might be expected. For further guidance on transients refer to IEEE C62.41. tr.

\subsubsection{Normal input sources.}

a. The normal source for the UPS system has the following characteristics:

Voltage/Phase/Wire

No. of Input Sources

Power Factor Lagging at

Nominal Input Voltage

Frequency

System Grounding Solid,

High Resistance, Ungrounded

Available Short-Circuit

Current (amperes rms sym.

at rated voltage for a bolted

three-phase fault)

Steady-State Voltage

Variations

$\%$

$\%$

$\%$

$\%$

Frequency Variations

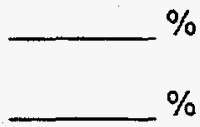

\section{NORMAL AC SOURCE}

STANDBY GENERATOR SOURCE

[Single/Dual]

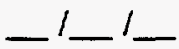
$\%(+)$ $\%(-)$

b. Transient conditions which may be expected are:

- Motor starting transients causing voltage surges of [200]\% with a duration of $[50]$ microseconds. 
- Ground fault on high-resistance grounded systems causing [260]\% voltage surges of [50] milliseconds. Unfaulted phases may rise to full line-to-line voltage for extended periods of time.

\section{ATTENTION:}

Internal bypass source parameters should be the same as those given for the normal source input, above. If the input may come from more than one source (such as commercial power or standby generator), then enter the worst case parameters.

3.2.2 Internal bypass source. The internal bypass source for the UPS system has the following characteristics:

Voltage

Frequency

Phase/Wire

System Grounding Solid, High Resistance, Ungrounded

Available Short Circuit Current (amperes rms sym. at rated voltage)

Steady-State Voltage Variations

Frequency Variations (+) $(-)$

Total Harmonic Distortion $\%$ 


\section{ATTENTION:}

Supply the desired source parameters for the critical loads below. The short circuit current rating should come from the same design analysis that dictated the size of the protective circuits. trom thotw

3.2.3 UPS module output. The UPS inverter output will normally be the source of supply to the uninterruptible ac bus which has the following nominal characteristics:

Voltage

Frequency

Phase/Wire

System Grounding Solid, Ungrounded

Short Circuit Rating (amperes rms sym. at rated voltage)

\section{ATTENTION:}

Consult with the onsite structural engineer regarding seismic requirements. Revise or delete all of paragraph 3.2.4 as necessary. Enter the site's seismic zone using the appropriate builoing code.

3.2.4 Seismic requirements. Equipment shall be designed for seismic zone [ $[$ _ ] in accordance with [ICBO UBC.] [___.] Submit the analysis used to qualify the UPS to be furnished for the seismic zone indicated above. Valid methods are shown in paragraph 3.2.4.2, below.

3.2.4.1 Supports. Equipment and equipment supports shall be designed to withstand and maintain their structural integrity when exposed to seismic loading indicated in 3.2 .4 , above. The equipment structures shall be completely self-supporting.

3.2.4.2 Demonstration of integrity. Demonstrate the equipment's ability to withstand and maintain its structural integrity when subjected to the forces resulting from the seismic conditions specified herein. This shall be accomplished in one or a combination of the following methods:

a. Predict the equipment's performance and response to a seismic force by mathematical static analysis;

b. Test the equipment under simulated seismic conditions (static or dynamic testing); or 
c. Utilize previous seismic qualification of the equipment and demonstrate applicability under the seismic conditions specified herein.

ATTENTION:

The following subparagraph reflects seismic requirements under the Uniform Building Code (ICBO UBC). Revise as required under other building code jurisdictions.

3.2.4.3 Seismic loading method. The seismic loading on the equipment and its supports shall be obtained by multiplying the weight of components by the horizontal seismic acceleration coefficient. The force shall be assumed to act in any lateral direction.

3.2.4.4 Friction. Support design shall not include friction in resisting the lateral shear load.

3.2.4.5 Maximum stresses. The maximum stresses under seismic loading, combined with all other load effects, shall be within the normal allowable material working stress limits as set forth in the appropriate design standards and codes listed in this specification.

3.2.4.6 Deformation. Deformations resulting from the combined influence of normal operating loads and seismic loads shall be investigated to verify that they will not impair structural integrity.

3.2.4.7 Review documents. Provide for review, upon request, all calculations and test results utilized for seismic qualification of the UPS, its support structures, and any anchors. Said documents shall be signed and sealed by a registered professional engineer.

3.2.5 Operating environment. Each UPS and associated equipment shall meet the performance requirements of this specification while operating under the environmental conditions specified below. Any environmental effects on the life expectancy of the UPS shall be clearly identified by Seller in appendix A.

a. Elevation: [ $] \mathrm{ft}$ above mean sea level.

b. Indoor Ambient Temperature: Range [] to $L]^{\circ} \mathrm{F}$.

c. Indoor Relative Humidity: Range [ $]$ to [ $] \%$, [noncondensing].

d. Anchorage: UPS system shall be [bolted] [welded] to [floor support.] .]

e. Tropicalization and Fungus Protection: [Is] [Is not] required.

f. Location: [Indoors] [Outdoors]. 
ATTENTION:

Use the entire following paragraph if replacing an existing UPS system or if total UPS system input and output current values are known, including amount of current required to recharge batteries from a fully-discharged state. Otherwise, use only item $f$ (Cable Entry).

t.t.

3.2.6 Conformance with existing cables. The UPS system shall accommodate the following existing facility cables.

\section{ATTENTION:}

Enter the number and size of cables for each conduction path. The speciffer must also indicate whether the cables will enter the UPS from the top or the bottom of the enclosure.
a. Normal Supply:
No/ph
Size
[AWG] [kcmil]
b. Bypass Supply:
No/ph
Size [AWG] [kemil]
c. UPS Output (Uninterr. AC Bus):

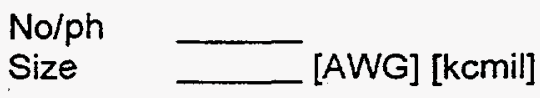
d. DC Supply:
No/ph
Size
e. Enclosure Ground:
[2/0 AWG] [4/0 AWG]
f. Cable Entry:
[Top] [Bottom]

\subsubsection{Overload capacity.}

a. $30-$ Second Overload: $150 \%$ of rated.

b. 25-Millisecond Overload: $200-300 \%$ of rated.

3.2.8 Efficiency. The UPS system shall operate as specified at the following efficiencies, where efficiency is defined as power in/power out with the battery on full charge:

a. Full load at unity pf $=92 \%$ to $95 \%$

b. Half load at unity pf $=85 \%$ or better

c. Full load at 0.8 lagging of $=92 \%$

d. Half load at 0.8 lagging $\mathrm{pf}=85 \%$ 


\section{DOE-SPEC-3021-97}

\subsection{Design and construction.}

3.3.1 General. The UPS system shall consist of a UPS module and storage battery rated to supply the requirements for the critical load as specified herein.

3.3.1.1 Source and output. The internal bypass source and the inverter output shall be connected to the ac bus via a high-speed static transfer switch. The static transfer switch shall automatically transfer the ac bus to the internal bypass source only if it is available within the tolerances noted in paragraph 3.2.2 or upon a drop in output voltage or variation of frequency as specified in paragraph 3.3.2.1.

3.3.1.2 Power interruption interval. The power-interruption interval during the transfer from the inverter to the internal bypass source shall not exceed the limits defined in paragraph 3.3.5.4. If specified in paragraph 3.3.5.2, the transfer switch shall automatically retransfer the ac bus back to the inverter output upon restoration of normal conditions and after a suitable time delay to avoid cycling during slow clearing of external faults and during inrush conditions. This transfer shall always take place for the inrush loads listed in paragraph 3.3.5.3. A transfer in either direction shall not cause a disturbance to the critical loads. Provide the means for the Owner to manually inhibit automatic retransfer via the static transfer switch. Transfer in either direction shall not cause a disturbance to the ac load(s). Transfer shall require the inverter output to be in synchronism with the bypass ac source, except for an inverter failure. For inverter failure, the transfer shall complete regardless of phase angle. The UPS module shall provide an alarm whenever a transfer to the internal bypass source takes place. Include a suitable time delay for this alarm to avoid alarming on momentary transfer.

3.3.1.3 Manual transfer. Make provisions to transfer the ac bus manually to the external maintenance bypass source for maintenance of the static switch with a make-before-break switch for uninterrupted transfer of power to the critical loads.

\subsubsection{Inverter.}

ATTENTION:

The following are guidelines for providing information about inverters, below:

The voltage regulation of most UPS systems is around $\pm 5 \%$.

The transient response to a $100 \%$ step change in load should hold the output voltage to within $\pm 10 \%$ of nominal and the output should recover to within $\pm 3 \%$ of nominal in 3-5 cycles.

As a guideline, the total harmonic distortion (THD) should not exceed $5 \%$, and the maximum content of any single harmonic should not exceed $3 \%$. 
The inrush characteristics must come from an analysis of the loads themselves.

3.3.2.1 Output voltage. The UPS inverter shall maintain the output voltage within +[]$]$ and -[]$\%$ and output frequency within $+[-]$ and $-[\quad[\%$, when delivering no load, through rated continuous output of [_] kVA at [_ ] pf lagging through unity pf with steady-state variation in normal supply voltage and frequency as specified in paragraph 3.2.1 in any combination, or with variations in the dc power supply voltage as specified in paragraph 3.3.4.

3.3.2.2 Transient response. Upon sudden application or removal of $[-] \%$ load in one step, the transient response of the UPS systems (with transfer switch) shall not permit the voltage to deviate simultaneously more than $+\left[{ }_{[}\right] \%$ (on peak-to-peak measurement basis) and it shall recover to within $+\left[\_\right] \%$ of nominal voltage in less than $\left[\_\right]$cycles. Frequency shall remain within the steady state requirements at all times (paragraph 3.3.2.1 above).

3.3.2.3 Harmonic content. The total harmonic content of the UPS inverter output shall be less than $[\quad] \% \mathrm{rms}$. The content of any single harmonic shall be less than []$\%$ rms.

3.3.2.4 Inrush. The inverter shall tolerate a maximum expected inrush of ] kVA for a duration of [ _ ] milliseconds at rated voltage and at ] lagging power factor.

ATTENTION:

The term "thermal degradation" means that no components within the system shall suffer any change in performance due to the worst case operating temperatures in the system while the system is operating within specified limits.

3.3.2.5 Operating constraints. The UPS system shall operate continuously within the specified voltage and frequency limits, from no-load to full-load conditions without thermal degradation. The UPS system inverter shall operate within its specified output boundaries when supplying the inrush load by transferring the inrush demand, if required, to the internal bypass ac power source through operation of the transfer switch.

\subsubsection{Synchronization.}

a. The UPS system inverter output shall be frequency and phase synchronized to the internal bypass source frequency (as indicated in subparagraph b. below). In the event the Owner's electrical distribution system frequency is outside the limits given in paragraph 3.2.1, the inverter shall revert to its own internal standard which shall maintain the output frequency 
within the specified limits. Upon restoration of the Owner's electrical distribution system frequency to within specified limits, the inverter shall automatically synchronize with it at a slew rate of $1 \mathrm{~Hz} / \mathrm{s}$ or less. Indication of synchronism shall be provided on the UPS system control panel.

\section{ATTENTION:}

Synchronization is usually based on the frequency difference of the two sources being within less than $0.5 \mathrm{~Hz}$ and the phase difference being less than 2 degrees.

atr.t.

b. Synchronization between the inverter output and internal bypass source shall be defined to be coincidence of frequency $\pm\left[\quad \mathrm{Hz}\right.$ and coincidence of phase $\pm\left[\_\right]$degrees.

3.3.2.7 Interlocks. Provide interlocks to prevent a manual transfer from the inverter output to the external maintenance bypass source and internal bypass under normal conditions if it is outside the following limits:

a. Bypass voltage (internal or external) is more than $10 \%$ higher or lower than nominal

b. Voltage difference between inverter output and bypass source (internal or external) is greater than $10 \%$ of the bypass voltage

c. Bypass frequency (internal or external) is more than $\pm 0.5 \mathrm{~Hz}$ from the nominal value specified in 3.2.2

d. The two sources are not synchronized to within 2 degrees

3.3.2.8 Current limiting. The UPS system inverter shall be equipped with a complete automatic current limiting feature which prevents the output from exceeding the maximum safe rating of the inverter and protects it against overloads or short circuits at the output. As long as the overload is present, the limiting feature shall limit the output current to a value which will not damage the inverter or cause its protective devices to operate. Once the overload is removed, the inverter shall automatically resume operation at normal voltage. In the event of the load limiting feature failure, backup protection shall be provided which will trip the inverter and transfer the load to the internal bypass source. This condition shall be indicated locally and through a set of alarm contacts for the Owner's annunciator. 


\subsubsection{Rectifier/Charger.}

3.3.3.1 Controls. The rectifier/charger shall include the following adjustments and controls:

\section{ATTENTION:}

Enter the amount of float voltage adjustment and equalization voltage adjustment required. $A \pm 2 \%$ adjustment should be the minimum specified with $\pm 3 \%$ being high enough to accommodate almost any battery and battery room temperature condition.

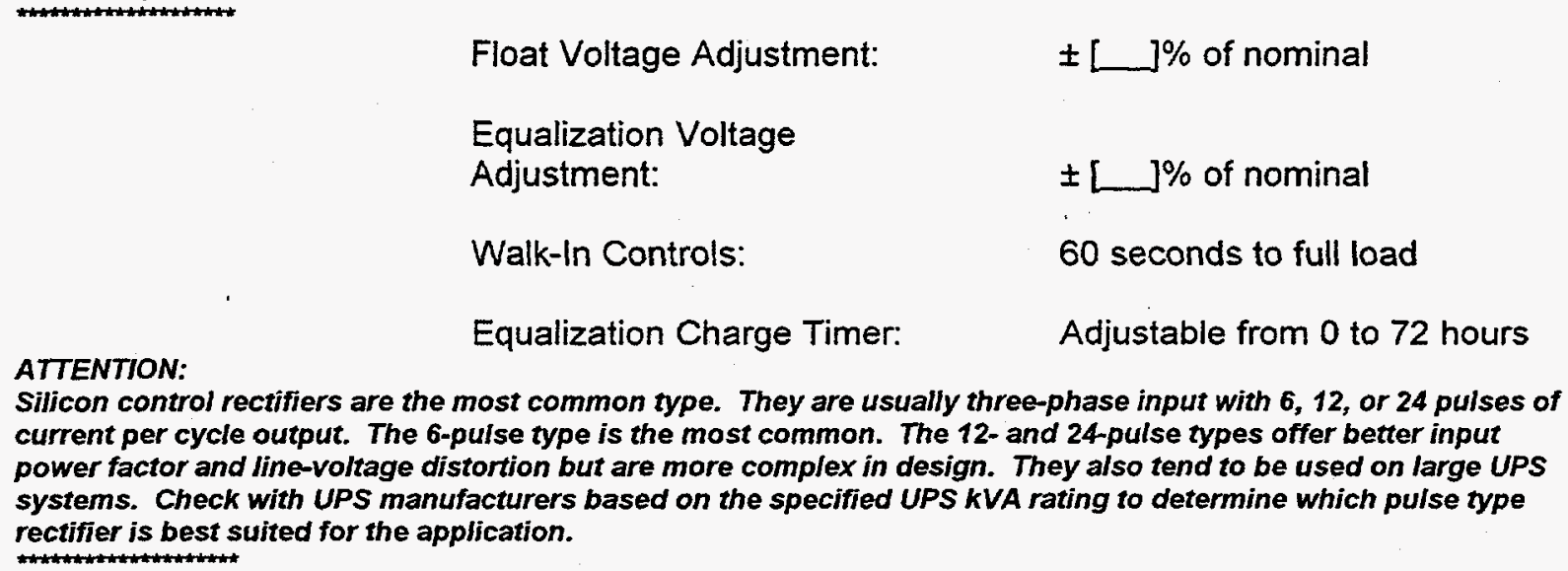

3.3.3.2 Type. The internal dc source rectifier/charger for the UPS system shall be of the [6] [12] [24]-pulse silicon-controlled rectifier type, for operation from Owner's normal ac source. The output of the rectifier shall be the current required to supply the UPS system inverter and supply the charging requirements of the UPS system battery. The rectifier output shall be self-regulating and maintain the output voltage constant within the input source variations described in paragraph 3.2.1.

3.3.3.3 Load limiting. The rectifier/charger shall be equipped with a completely automatic load-limiting feature which prevents the output from exceeding its maximum safe rating. In the event of failure of the load-limiting feature, backup protection shall be provided to trip the unit.

3.3.3.4 Harmonic reduction. The rectifier shall be a full-wave controlled type using silicon controlled rectifiers (SCRs) in both the positive and negative legs to reduce even-ordered harmonics. The total harmonic distortion (THD) of current drawn by the UPS shall not exceed $5 \%$.

3.3.3.5 Output voltage. The rectifier/charger normal output voltage shall be adjustable and shall be set to the battery manufacturer's 
specified float charge voltage. Following a prolonged discharge of the battery (see paragraph 3.3.3.6, below), the output voltage shall provide the option of automatically switching to the battery manufacturer's specified equalize charge voltage for a period of time set by the timer specified in paragraph 3.3.3.6, below or continue charging at the predetermined float level.

3.3.3.6 Charge timers. The rectifier/charger shall be equipped with two automatic equalization charge timers to control the output voltage. Timer 1 shall be a fixed two-minute timer that prevents application of an equalization charge if the ac input power loss is less than two minutes. Timer 2 shall be an adjustable timer that can be selected from 0 to 72 hours in increments of 1 hour. This timer shall initiate and control the length of the equalization charge. At the end of the equalization charge time the charger shall automatically revert to float charge. [Also provide manual equalization capability.]

3.3.3.7 Temperature compensation. The rectifier/charger shall be equipped with temperature compensation controls to limit current drawn by the battery string dependent on the battery cell(s) skin temperature.

3.3.3.8 Filtering. The rectifier/charger shall limit ac ripple voltage on the dc bus to $5 \%$ maximum of the rated ac input voltage.

3.3.3.9 Recovery control. The rectifier/charger shall include circuits and controls to recover gradually, following a loss of ac input power. This "walk in" circuit shall control the dc output from $0-100 \%$ of normal operation over a period of less than 60 seconds. The output voltage shall be increased gradually until it reaches the required charge voltage or current limiting takes place.

3.3.4 Battery power supply. In the event that the battery is disconnected for maintenance, the UPS shall continue to operate in a power-conditioning mode and the output characteristics of the UPS shall not be degraded. Upon failure of the normal source for the UPS system, the load shall continue to receive power from the dc system, which shall have the following characteristics:

\begin{abstract}
ATTENTION: battery manufacturer at a later date.

a. Battery Type:

b. Nominal Voltage, Ungrounded:
\end{abstract}

The following information concerning the backup battery must be obtained from the DOE Standard "Sealed Valve-Regulated Lead-Acid Storage Batteries" or "Flooded-Type Lead-Acid Storage Batteries." Remember - the short-circuit current capability of a sealed, valve-regulated battery is higher than the same size flooded-cell battery. If a new battery system is purchased with the UPS system, items b. through e. may be provided by the

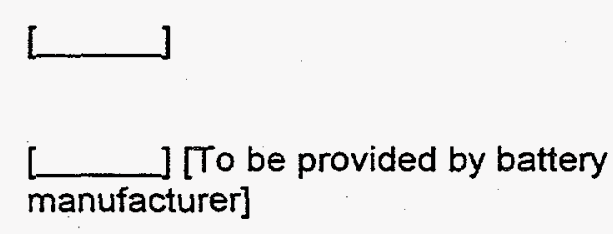

manufacturer] 


\section{DOE-SPEC-3021-97}

c. Battery Float Voltage: $\underset{\text { manufacturer] }}{[}[$ To be provided by battery

d. Voltage Variation (battery equalized and discharged respectively):
[ 1$]$ [To be provided by battery manufacturer]

e. Short-Circuit Current (at nominal voltage):

[ $A$ dc] [To be provided by battery manufacturer]

\subsubsection{Static transfer switch.}

\section{ATTENTION:}

The transfer conditions should be dictated by the needs of the connected load. Some typical values are: drop-in input voltage below $90 \%$ for $5 \mathrm{~ms}$ and $\pm 5 \%$ frequency deviation for $50 \mathrm{~ms}$.

3.3.5.1 General. The transfer switch shall transfer from the inverter output to the internal bypass source when any of the following conditions occur:

a. The inrush load exceeds the inverter capability as listed below in paragraph 3.3.5.3.

b. Drop of inverter output voltage below $\left[\_\right] \%$ of nominal voltage for more than [_] milliseconds.

c. Deviation of inverter output frequency of $\pm[\quad] \%$ of nominal value for [_] $]$ milliseconds.

d. Inverter output voltage is outside regulating band in excess of transient response period (paragraph 3.3.2.2).

ATTENTION:

The retransfer is normally selected by an auto/manual control switch, so the fill-in should show that it shall transfer.

3.3.5.2 Retransfer. The transfer switch [shall] [shall not] retransfer to the inverter upon restoration of normal conditions; however, it shall always retransfer after inrush conditions. 
ATTENTION:

The inrush capabilities are dictated by the connected load and the internal bypass short circuit capability required is dictated by the clearing time of the protective circuits in the internal bypass source.

3.3.5.3 Inrush. The transfer switch shall be capable of carrying the maximum expected inrush of [ ] ] kVA for [] milliseconds at rated voltage and at $\left[\_\right.$lagging power factor. It shall also be capable of carrying internal bypass source available short circuit current specified for $[$ ] milliseconds.

\section{ATTENTION:}

The transfer time should ideally be instantaneous. A realistic time for both the load and the UPS switch is less than $4 \mathrm{~ms}$ or $1 / 4$ of a cycle.

that 4 ms

3.3.5.4 Transfer time. The total transfer time, including sense time, from the sudden loss of inverter output to the transfer to the internal bypass source shall not be more than [ $\_$] milliseconds.

3.3.5.5 Output current. The static transfer switch shall be capable of continuously carrying the rated output current of the UPS system and the inrush current and short-circuited currents listed in paragraph 3.3.5.3.

3.3.5.6 Operations. The static transfer switch shall be capable of the following operations:

a. Continuous operation at full load current.

b. Switching from normal inverter operation to internal bypass and retransfer back following a 10-second delay. The switch shall handle the inrush currents involved in the transfer (see paragraph 3.3.5.3).

\section{ATTENTION:}

Isolation transformers are used at the input of the UPS module to attenuate the passage of noise or transients. This section requires that the user enter the specific parameters of the transformers to be used.

\section{t.t.}

3.3.6 Isolation transformer. The UPS isolation transformer shall have the following characteristics: [ $L$ ] kVA, [1] [3]-phase, $\left[\_\right]^{\circ} \mathrm{C}$ temperature rise, $\left.L\right]$ ] Hz, dry-type transformer primary rated [ ] ] V, [wye] [delta], secondary rated L ] $V$, [wye] [delta], class [ ] insulation, with hot-spot temperature not to exceed [ ] ${ }^{\circ} \mathrm{C}$ rise over []$^{\circ} \mathrm{C}$ ambient. High-voltage winding shall have two []$] \%$ taps above nominal and four $L] \%$ taps below nominal. The transformer shall have $[-] \%$ impedance (minimum) on its own base. Low-voltage neutral shall be [grounded.] [brought out for external connection.] 


\subsubsection{Alarms.}

\section{ATTENTION:}

Designate a preference for either an instantaneous or time delayed alarm, as well as whether the alarm contact should be normally open or closed.

a. The UPS system will initiate an [instantaneous] [time delayed] alarm signal upon loss of normal and bypass source.

b. Alarm contacts shall be [normally open] [normally closed].

3.3.8 Maintenance bypass switch. Provide a manually-operated maintenance bypass switch, make-before-break type, to isolate the inverter and static switch for maintenance and repair. The switch operation shall be inhibited if the external bypass source is outside the limits specified in paragraph 3.3.2.7.

3.3.9 Materials. All materials shall be new and shall be selected by the Seller to perform as specified herein. Like parts shall be interchangeable. Workmanship shall be neat, comply with recognized industry standards, and shall be in accordance with accepted engineering practices.

3.3.10 Enclosure. The UPS system shall be housed in NEMA ICS 6 type-[1] enclosure, heavy duty, reinforced steel, freestanding cabinet which requires access only from the front (hinged front panels). Unless specified otherwise in paragraph 3.2.6, make provisions for Owner's control and power cables to enter either the top or the bottom of the cabinet.

3.3.10.1 Ground bus. Provide a copper ground bus with a cross section of at least $1 / 4 \times 1$ inch in the cabinet, with connections to all ac-system neutrals and compression-type connector for the Owner's copper grounding cable (such as Burndy "YA" or equivalent.)

3.3.10.2 Access. Provide quick and convenient access, preferably by a hinged door or panel, to the protective devices and control circuit disconnecting devices provided.

3.3.10.3 Lifting devices. Provide suitable lifting devices (e.g., lifting eye bolts) for each unit.

3.3.11 Wiring. Provide control wiring and termination facilities in accordance with the following requirements. 
ATTENTION:

Variations in wiring which may be needed, depending on possible special needs in certain systems:

- 18 AWG teflon type-E hook-up wire for modules and subpanels or elsewhere if space and/or extreme flexibility are critical

- Special stranding where moderate flexibility is important

- Shielding and/or cross-section compatible with cables of special construction.

3.3.11.1 General. Wiring shall be $600 \mathrm{~V}$, stranded copper switchboard wire with type SIS insulation (heat-, moisture-, and flame-resistant). Wiring shall be free of abrasions and tool marks, including nicks and fraying from stripping of insulation. Wiring shall also:

a. Have a minimum bending radius of $1 / 4$ inch

b. Have sufficient surrounding space to avoid jamming near terminal blocks, or between terminal blocks and wireway

c. Be adequately supported to prevent sagging and breakage, caused by vibration or shock in transit

d. Be continuous within a panel or unit; that is, with no splicing

3.3.11.2 Bundling. All wires for a given circuit, or a maximum of twelve wires, shall be in one bundle to facilitate tracing for trouble-shooting or removal for changes. The wire bundle shall be carried between a clamp on the door and a clamp on the fixed portion of the board or cabinet. The clamps shall be adjacent to the hinge and shall be between 12 and 24 inches apart with the door fully open.

3.3.11.3 Rating. Wire shall be of adequate rating for the current to be carried.

3.3.11.4 Wire size and insulation selection. Use nothing smaller than 14 AWG wire, except 16 AWG may be used for circuits where maximum current does not exceed $5 \mathrm{~A}$. Wire size and insulation selection shall conform to and comply with the following: no overheating of the conductor and no insulation damage to adjacent conductor shall occur when wires associated with dc and ac control circuits carry $20,000 \mathrm{~A}$ and $10,000 \mathrm{~A}$ rms symmetrical respectively, for 25 milliseconds.

3.3.11.5 Flexible cables. Where cables must be carried across hinges to devices mounted on doors, use extra-flexible, ICEA Class d stranding conductors. 


\section{DOE-SPEC-3021-97}

3.3.11.6 Clamps. Clamps used other than in bundles (see paragraph 3.3.12.2) shall be spaced uniformly at distances no greater than 24 inches apart.

3.3.11.7 Terminal boards. Provide terminal boards for all controls, instruments, annunciators, meters, and relays requiring external cable connections.

3.3.11.7.1 Terminations. Seller's wiring shall be terminated on terminal boards or equipment with insulation-gripping insulated wire terminal lugs.

3.3.11.7.2 Lugs. The tongue portion of the terminal lugs shall be [ring-type].

3.3.11.7.3 Tools. Use ratchet-type tools when attaching lugs to wires, to avoid loose connections due to insufficient pressure while crimping.

3.3.11.7.4 Clamps. Box-clamp or saddle-clamp terminals are not acceptable because of possible damage to wire ends. Provide relays and other devices without saddle clamps or remove the clamps in panel assembly and use ring-type lugs for panel wiring these devices.

3.3.11.7.5 Terminal types. No solder or "push-on" or "quick" type terminals shall be used except:

a. Solder-type for pushbuttons, or indicating lights, when specified

b. Solder-type for flat resistors when specified

c. Push-on for indicating lights when specified.

3.3.11.7.6 External connections. Owner's external connections will be via cables with $[12,14,16]$ AWG, stranded copper conductors and lugs similar to those described above. Terminals for the Owner's external connections shall be arranged for consecutive connection of conductors within one cable. One external wire shall be connected to each outgoing terminal point.

3.3.11.7.7 Internal wiring. In Seller's internal wiring, not more than two wires shall be connected to one terminal block point. Not more than one wire shall be in any terminal lug. (Individual termination in each lug is necessary, to facilitate trouble-shooting.) 
3.3.11.7.8 Short-circuit protection. If accidental short circuiting of certain wires could result in malfunction of equipment such as closing or tripping of a circuit breaker, do not terminate these wires on adjacent terminal block points.

3.3.11.7.9 Continuity testing. Make provision for conveniently field testing the continuity of all control circuits.

3.3.11.7.10 Markers. Provide wire markers on both ends of each wire that is longer than 12 inches. Wire markers shall have indelible designations in accordance with Seller's wiring diagrams. The markers shall be Thomas \& Betts Co., Inc. "WB Vari-Temp" or "WSL Self-Laminating," or equal.

3.3.11.7.11 Space. Provide adequate space on both sides of the terminal blocks for connecting wires and for wire markers. To allow for stripping and bending of incoming cables, locate terminal strips at least 8 inches away from cable entrances at the top and/or bottom of cabinets.

3.3.11.7.12 Current transformer connections. Shorting terminals shall be provided for any current transformer connections.

3.3.12 Cooling system. Cooling shall be by forced air. Locate low-velocity, permanently-lubricated, redundant fans (the second to automatically start on failure of the first) on the power-switching module directly below critical components to ensure that the cooling air path is not obstructed. Fan failures shall cause annunciation and an audible alarm to sound as specified in paragraph 3.5.1.7. Equip all air inlets with standard type filters replacable from outside the unit. Provide expanded metal guards on all air inlet and exhaust openings. Each fan shall be on an individual ac-branch circuit.

\subsection{Sound control.}

3.4.1 Allowable sound level. The Owner will review the sound level of equipment covered by this specification with respect to the permissible exposure limits for personnel as defined in 29 CFR 1910.95. Accordingly, the sound level measured at a distance of five feet from the outline of the equipment shall not exceed $75 \mathrm{~dB}(\mathrm{~A})$.

3.4.2 Acoustical treatment. If Seller expects the maximum sound level of the equipment to exceed the specified allowable limit at a distance of five feet, Seller shall use acoustical treatment features subject to Owner's review and acceptance to achieve the sound control design objectives. 


\section{DOE-SPEC-3021-97}

3.4.3 Additional review. If the expected maximum sound level of the equipment exceeds the specified requirements, provide the following sound level data (both attenuated and unattenuated) at equipment design point and for at least two other operating conditions.

a. Maximum sound pressure level measured under "free field" conditions at a distance of five feet from the outline of equipment shown in decibels on the " $A$ " scale, at the octave band center frequencies ranging from 31.5 to $8000 \mathrm{~Hz}$.

b. Calculated maximum sound power level of the equipment shown in decibels at octave band center frequencies ranging from 31.5 to $8000 \mathrm{~Hz}$ and referred to a base of $10-12 \mathrm{~W}$.

\subsection{Instrumentation and controls.}

3.5.1 Protective and control devices. The UPS system shall be equipped with the following protective and control devices in addition to those specified in paragraph 3.3.7:

3.5.1.1 Transient overvoltage protection. UPS system self-protection against transient overvoltages in dc and ac control and power circuits. This protection shall be built into the equipment with no special external connections, configuration of leads or connection of any external equipment required.

3.5.1.2 Breakers. Three thermal magnetic molded-case circuit breakers rated for operation in accordance with paragraph 3.2.1; one on the ac-normal input side of the UPS rectifier, one on the output side of the UPS inverter, and one in series with the internal bypass source. Status of all three breakers shall be indicated light on the UPS control panel.

3.5.1.3 Loss-of-power relays. Loss of power relays (all three phases) for both ac supply and bypass inputs (internal and external). Actuation of these relays shall initiate alarm (paragraph 3.3.7)

3.5.1.4 DC low-voltage protection. Inverter protection by the following adjustable-set-point, low-input voltage circuits:

- DC low-voltage warning (alarm only)

- DC undervoltage trip (alarm and trip action)

3.5.1.5 Overvoltage protection. Overvoltage relay connected across the rectifier output. Actuation of this relay shall trip the normal internal dc source if necessary to protect the inverter and shall operate an alarm device. 
3.5.1.6 Inverter protection. Protective devices connected in the inverter output circuit to protect the Owner's uninterruptible ac bus against excessive voltage and frequency variations, overvoltage, undervoltage, over-frequency, and under-frequency. These protective devices shall trip the inverter off the line after a time delay, to override transients and initiate transfer of the Owner's uninterruptible ac bus to the internal bypass supply.

3.5.1.7 Cooling failure alarm. A forced-air cooling system failure alarm.

3.5.1.8 Alarm indicators. Local indication of any alarm condition detected by the UPS system by lights and local annunciator. In addition, provide a single form- $C$ type contact that operates on any alarm for the Owner's remote annunciation.

3.5.1.9 Relay contacts. All alarm and protective-relay contacts rated 12 or $24 \mathrm{Vdc}, 5-\mathrm{A}$ make-and-carry, and 1.1-A noninductive interrupting duty.

3.5.2 Panel-mounted items. Provide the following items and quantities and mount on the instrument panel of the UPS system:

a. $1 \mathrm{dc}$ voltmeter

b. $1 \mathrm{dc}$ ammeter

c. 1 input ac ammeter [with phase-selector switch]

d. 1 input ac voltmeter [with A-B, B-C, C-A phase-selector switch]

e. 1 output ac ammeter [with phase-selector switch]

f. 1 output ac voltmeter [with phase-selector switch]

g. 1 output frequency meter

h. 1 synchronizing verification light

i. 1 indicating lamp each for UPS load on NORMAL, STATION BATTERY, and BYPASS

j. 1 indicating lamp for LOW DC VOLTAGE

k. 1 inverter capacitor charge-discharge switch (if required)

I. 1 indicating lamp or other alarm for FORCED AIR COOLING SYSTEM. FAILURE, if forced air cooling is provided 


\section{DOE-SPEC-3021-97}

3.5.3 Control and indicator circuits. All control and indicator circuits shall be either $120 \mathrm{Vac}$ or $120 \mathrm{Vdc}$ or lower. The UPS shall include step-down transformers if necessary.

3.5.4 Access. All diodes, transistors, potentiometers, and like items shall be inspectable and removable from the front of the cabinet (hinged panels open) without requiring access to rear of the cabinet. All operating instruments, adjustments and controls shall be operable from the front of the panel. Fuses shall be accessible by opening hinged front panels.

3.5.5 Identification. Clearly identify each relay, meter, switch, indicating light, and like item functionally by a black background, white-lettered, multi-layer nameplate with corrosion-resistant, steel, self-tapping screws. The inscription shall describe the function of the device and be subject to the Owner's review and comment.

3.5.6 Connectors. Provide the same compression-type connectors for the attachment of ac-input, ac-output, and dc-input cables to suitable connection pads.

3.5.7 Pushbuttons. Pushbuttons, when provided, shall be heavy-duty, oil-tight type recessed or provided with shroud ring.

3.5.8 Fuses. Control fuses shall be suitably rated, $250 \mathrm{~V}$ minimum cartridge type. Miniature fuses are acceptable on logic circuits and PC boards.

3.5.9 Lights. All indicating lights shall use extra-long-life, low-voltage lamps. Series-connected, current-limiting resistors may be used if required.

3.6 Spare parts. Provide a list of recommended spare parts identifying each and the specific subassembly to which it applies. Indicate the expected life of the parts requiring replacement and the minimum recommended inventory of the spare parts for installation startup, continuous operation, and maintenance. State whether the recommended spare part is a stock item or a special item, provide name and location of the nearest supplier, and indicate the approximate lead time required for delivery.

3.7 Special tools. Provide all special tools necessary for installation, startup, operation, maintenance, and adjustment of the equipment and of the accessories provided. Provide a list of all special tools provided, identifying the function of each tool and the specific items for which it is used.

3.8 Surface preparation and coatings.

3.8.1 Corrosion protection. Fabricate all UPS enclosure metal surfaces from corrosion-resistant materials and as a minimum, protect by application of a primer and a top coat. Application of primer shall be in accordance with SSPC PA 1.

3.8.2 Documentation. Provide with the proposal, a complete description of the proposed corrosion protection and coating, including applicable cleaning and coating procedures.

3.9 Equipment marking. Attach a corrosion-resistant nameplate with clear legible writing, screwed in four places onto each assembled piece of equipment, at an easily-visible place. It shall provide all necessary information pertaining to the equipment but, as a minimum, 
include: manufacturer's name, type of equipment, serial number, weight ratings, and electrical ratings. Any special maintenance instructions shall also be shown on this or in other suitable location.

3.10 Installation. Installation will be by the Owner. If requested, Seller shall provide the services of a field service representative to provide technical advice for installation and startup. Scope of services shall be clearly stated in Seller's proposal. Provide adequate information covering installation requirements in time for Owner's use (see paragraph 4.0).

4. DOCUMENTATION

\subsection{General.}

4.1.1 Documents. Submit [3] sets of drawings and data required by the specification
and/or listed in paragraph 4.5 within the time specified for Owner's review.

4.1.2 Schedules. Submit with the proposal, a proposed schedule of work including equipment delivery dates in sufficient detail to demonstrate Seller's ability to perform the work within the Owner's required schedule.

4.2 Drawings. Submit drawings in the manner and within the time specified, showing purchase order number and item number(s), outline and overall dimensions, clearance dimensions, connection details, weights, sectional views showing functional parts, parts list and materials. These drawings shall also include, for each item provided by Seller, the following:

a. Dimensioned general assembly drawing showing arrangement of all major items, cable entrance locations (power and control), mounting details, required maintenance and operating clearances

b. Electrical schematic diagrams

c. Electrical wiring diagrams; internal and external connections

d. Installation details (paragraph 3.10)

e. Foundation requirements, loads, fastening details

4.3 Wiring diagrams. The system used for designation of control wiring shall show device identification with identified terminals, both arranged in reasonably accurate physical relationship, and shall provide sufficient information at wire termination to locate the other termination without recourse to supplementary routing tabulations. Seller is solely responsible for correctness of the internal wiring and for the proper functioning of the equipment being provided.

4.4 Instruction manuals. Provide in the manner, number of copies, and within the time limits set forth in the Purchase Order, instruction manuals outlining installation, operation, and maintenance requirements in accordance with Owner's requirements. The instruction manual shall also include information on theory of operation and a troubleshooting guide. Ship one copy of the instructions applicable to each component or group of components, if there are no differences, with the component(s), if no instructions are set forth in the Purchase Order. 
Three complete sets of vendor documentation are usually desirable.

a. Drawings showing batteries, interconnections, rack outlines, dimensions required for mounting, weight of racks and filled cells, and description of rack finish for each battery system

b. Cell outline including connector and battery terminal details, electrolyte levels, weight of assembled cell, separate weights of electrolyte, plates, and jar

ATTENTION:

Add the following paragraph when seismic requirements apply.

c. Seismic rack design and certification (see paragraph 3.2.4)

d. Type, catalog designation, and description of major components provided by Seller

e. Longest recommended storage time when batteries are shipped charged, and [wet] [dry]-charged; and Seller's storage and freshening charge recommendations

f. Field test recommendations, including performance tests

g. Test reports for factory tests, including capacity tests

\subsection{Datá submission schedule.}

\begin{tabular}{|c|c|c|c|c|}
\hline Item & Description & $\begin{array}{l}\text { Spec } \\
\text { Para }\end{array}$ & $\begin{array}{l}\text { Submittal } \\
\text { Date }\end{array}$ & $\begin{array}{l}\text { Review Req'd } \\
\text { Before Shipmnt }\end{array}$ \\
\hline a. & $\begin{array}{l}\text { Proposed schedule to } \\
\text { meet delivery date(s) }\end{array}$ & - & With proposal & Yes \\
\hline b. & $\begin{array}{l}\text { Preliminary dwgs with } \\
\text { sufficient information } \\
\text { for Owner to proceed } \\
\text { with design }\end{array}$ & - & With proposal & Yes \\
\hline c. & $\begin{array}{l}\text { Complete list of } \\
\text { exceptions }\end{array}$ & - & With proposal & Yes \\
\hline d. & $\begin{array}{l}\text { Seismic certification } \\
\text { before shipment }\end{array}$ & 3.2 .4 & L_] weeks & Yes \\
\hline e. & $\begin{array}{l}\text { Sound-level data } \\
\text { before shipment }\end{array}$ & 3.4 .1 & L_ ] weeks & Yes \\
\hline f. & $\begin{array}{l}\text { Recommended spare } \\
\text { parts list }\end{array}$ & 3.6 & $\begin{array}{l}\text { With proposal } \\
\text { and shipment }\end{array}$ & Yes \\
\hline g. & List of special tools & 3.7 & With shipment & No \\
\hline
\end{tabular}


DOE-SPEC-3021-97

$\begin{array}{lllll}\text { h. } & \begin{array}{l}\text { Storage and handling } \\ \text { instructions }\end{array} & 7.4 & \text { With shipment } & \text { No } \\ \text { i. } & 5.6 & \text { With shipment } & \text { No } \\ \begin{array}{l}\text { Certificate of } \\ \text { compliance }\end{array} & & & \end{array}$

\section{ATTENTION:}

Fabrication sequence may be required for those projects with strict quality assurance requirements.

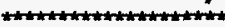

j. $\quad$ Fabrication sequence

k. Notification of shop tests

I. Documents for records

m.

n.

o.
Performance test results

n. Drawings "Certified for Construction"

Instruction manuals
5.3

5.4

$$
\begin{aligned}
& \text { L_] weeks } \\
& \text { after Purchase } \\
& \text { Order. }
\end{aligned}
$$

4.4 With shipment before fabrication test
No

7 days before No

With shipment No

[_] weeks Yes
before shipment

No

\section{QUALITY ASSURANCE}

5.1 General. Seller shall have methods to assure that items and services, including subcontracted items and services, comply with this specification.

5.2 Owner surveillance. Manufacturing, processing, testing and inspection operations affecting the equipment or material shall be subject to Owner surveillance.

5.3 Fabrication sequence. Prior to production, submit a fabrication sequence describing inspection and/or tests to be performed, for use in determining inspection points which the Owner may desire to witness. The Owner will advise Seller, prior to production, of those fabrication steps and shop inspection points that the Owner desires to witness.

5.4 Advance notice of tests. Seller shall give the Owner adequate notice, five working days minimum, prior to those fabrication steps and tests which the Owner desires to witness.

5.5 Deviations. All deviations to this specification shall be documented and referred to the Owner for disposition.

5.6 QA documentation. Provide the following quality assurance (QA) documents for the Owner's records:

a. Certificate of compliance, stating the following: "All work provided by Seller under this specification complies with all requirements of this specification and Owner-accepted deviations." 


\section{DOE-SPEC-3021-97}

b. Documents identifying deviations and their acceptance.

c. Performance test results.

6. INSPECTION AND TESTING

\subsection{General.}

6.1.1 Purpose of tests. Factory and field tests shall be conducted to determine that the materials and work are free from defects and to establish that the design and construction meet the requirements of this specification and the purchase order. Owner acceptance of the equipment shall not relieve the Seller of responsibility for meeting all the requirements of this specification.

6.1.2 Expense of testing. The cost of equipment, instruments, tools, personnel and other expenses incidental to the tests, including replacement of damaged materials and subsequent retests, shall be borne by Seller. This does not include Owner's expense in witnessing the tests.

6.1.3 Failed tests. If the UPS system or any part of it fails to meet the specified performance guarantees, correct/rework or replace the part which fails, as mutually agreed with the Owner.

6.1.4 Tests results. Submit test results for Owner review.

\subsection{Shop tests.}

6.2.1 Standard inspections. The UPS system shall be completely wired and adjusted at the factory and given standard inspections, wiring checks, and operation and dielectric tests to ensure completeness, adequacy and proper functioning of equipment in accordance with the requirements of this specification and standards and codes. Even though Seller performs the required tests and the equipment meets the acceptance criteria, Seller will not be relieved of the responsibility of providing equipment conforming to all the requirements of the specification.

6.2.2 Wiring tests. Factory test the control wiring as follows:

a. Perform a continuity test on each circuit.

b. Conduct an insulation-resistance test on each circuit with equipment connected, using a $1000-\mathrm{V}$ megger. The insulation resistance shall be not less than 25 megohms. (This test is not applicable to circuits containing semiconductors.)

6.2.3 NEMA tests. As a minimum, perform the following tests on the assembled UPS system in accordance with NEMA PE 1 and PE 5:
a. Light load
b. Synchronization 
c. AC-input failure

d. AC-input return

e. Transfer (forward and reverse)

f. Rated full load

g. UPS efficiency (half and full load)

h. Unbalanced load

i. Output voltage balance and phase

j. Overload capability

k. Short-circuit-current capability

I. Voltage rise

m. Voltage dip

n. Harmonics components

o. Audible noise

6.2.4 No-load/light-load testing. Test the assembled UPS system to verify its capability to operate continuously under no-load or light-load, as in paragraph 3.3.2.5. The test duration shall be a minimum of 24 hours.

6.2.5 Surge withstand tests. Conduct surge-withstand capability tests using the appropriate sections of IEEE C37.90 and IEEE C37.90.1 as a guide. The surge-withstand test wave shall be oscillatory with a 3000-V crest value in the first half cycle. The wave shape shall rise from 10 to $90 \%$ in 0.5 microsecond, then decay while oscillating at $100 \mathrm{kHz}$ with each peak being $60 \%$ of the preceding peak as shown in figure 2 of IEEE C62.41.

6.3 Field tests. After equipment is completely installed, acceptance tests will be performed by the Owner to demonstrate performance requirements as specified herein. Any rework necessary to bring the UPS system into compliance with this specification shall be at Seller's expense.

\section{PREPARATION FOR DELIVERY}

7.1 Cleaning. At the time of shipment, the equipment shall be clean inside and outside.

Remove all rust, oil, grease, chalk, crayon, and paint marks, and other deleterious material from all surfaces of the equipment. Touch up any cuts, nicks, or scratches to the coating system. 


\section{DOE-SPEC-3021-97}

\subsection{Packaging.}

a. Prepare equipment for shipment to protect it from damage during shipment and subsequent storage.

b. Protect all openings to prevent damage, corrosion, and entrance of foreign matter during shipment and storage.

c. Adequately support equipment for shipment. Crate or box loose parts for shipment, appropriately identified.

7.3 Labeling. Label and number packaging so that each section or assembly may be identified before being uncrated. Provide, in addition, the following:
a. Purchase-Order number
b. Seller's name
c. Delivery address as specified in the purchase order
d. Component(s) contained
e. "THIS SIDE UP" or "FRAGILE," as applicable

\subsection{Long-term storage.}

a. Provide recommended instructions for long-term storage.

b. The Owner will provide a storage environment similar to the installation location.

c. Provide storage and handling instructions, including descriptions for periodic inspections and/or storage maintenance to assure that no deterioration will occur during storage. Securely fasten one set of these instructions to the outside of the shipping unit. 


\section{APPENDIX A \\ ADDITIONAL TECHNICAL REQUIREMENTS}

A.1 Drawings and data. Provide with the proposal, the following drawings and data:

a. Sufficient illustrative and descriptive material to allow a detailed evaluation of the equipment being proposed. Seller-provided data shall indicate the guaranteed performance data, predicted performance, interface characteristics, installation instructions, and construction features of all Seller-provided equipment. The accuracy of such information and the compatibility of such information with overall performance requirements specified by the Owner, are the sole responsibility of Seller.

b. Preliminary general assembly drawing(s) indicating approximate overall dimensions and clearances needed for operation and maintenance or a statement that Owner's room dimensions are satisfactory to accommodate the UPS.

c. Completed data sheets included in appendix B. If a "base" and an "alternate" system are proposed, these sheets shall be copied and completed for each system. The words "base" and "alternate" shall be marked on the appropriate sheets.

d. Complete listing of codes and standards referenced in section 2.0 which the UPS system meets.

\section{ATTENTION:}

Include the following paragraph if an annual maintenance contract is required.

A.2 Maintenance contract. Submit a quotation with the proposal for annual maintenance of the UPS provided. Include details of the maintenance work, testing, and record keeping to be performed as a part of the maintenance contract. Submit with the proposal, a typical example of a maintenance report for a similar or equal UPS system.

A.3 Warranty. Submit with the proposal, complete details of the warranty to be provided for the UPS system. In the event that installation is not accomplished as scheduled, provide conditions for obtaining an extended warranty.

A.4 Experience. Provide a complete list (but not less than three) of installations of similar nature within the past five years as detailed below:

ITEM

2.

3. 
DOE-SPEC-3021-97

INTENTIONALLY LEFT BLANK 
DOE-SPEC-3021-97

APPENDIX B

UPS SYSTEM DATA SHEETS

B.1 UPS inverter input and output data.

a. Type

b. Output

c. Output power factor

d. Output voltage

e. Output frequency

f. Output stability:

- $A C$ voltage

- Frequency

g. Required input stability to achieve rated output stability under steady-state operation (paragraphs 3.2.1 and 3.3.4):

- $A C$ voltage

- Frequency

- DC voltage $(\min / \max )$

h. Maximum total harmonic content of output

i. Maximum single harmonic content of output

j. Short circuit currents (paragraphs 3.2.1 and 3.2.4):

- Maximum permissible current in normal ac input circuit

- Maximum permissible current in $d c$ input circuit
[Ferro-resonant] [Stepwave] [PWM]

J kVA

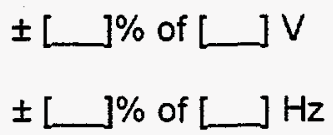

$\pm[\quad] \%$ of [ $[-] \mathrm{Hz}$

\pm[] L of $[-] \mathrm{Hz}$

L I ] $] V$

L $] \% \mathrm{rms}$

$1 \% \mathrm{rms}$

[_] A rms symmetrical

[]$A$ 
- External fault carrying capability of inverter:

- Current

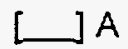

- Duration

[] $\mathrm{msec}$

k. DC input current required:

- No load, floated battery

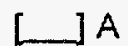

- Rated load, floated battery

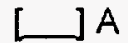

- Rated load, equalized battery

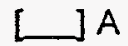

- Rated load, discharged battery

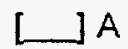

1. Voltage regulation (see paragraph 3.2.1)

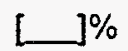

m. Frequency regulation (see paragraph 3.2.1)

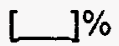

n. Overload capacity at full voltage:

- For 30 seconds [] $\mathrm{kVa}$

- For 25 milliseconds $\mathrm{kVa}$

o. Overall efficiency:

- $100 \%$ load at $1.0 \mathrm{pf}$

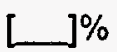

- $50 \%$ load at $1.0 \mathrm{pf}$

- $100 \%$ load at $0.8 \mathrm{pf}$

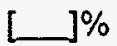

- $50 \%$ load at $0.8 \mathrm{pf}$

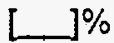

p. Response characteristics:

- Percent deviation in steady-state voltage output required to initiate transfer to bypass supply 
DOE-SPEC-3021-97

- Percent deviation in steady-state frequency required to initiate transfer to bypass supply before out-of-synchronism conditions develop $\mathrm{j} \% \mathrm{~Hz}$

- Percent deviation in voltage by instantaneous measurement method and duration to reach steady state:

- $100 \%$ load application []$\%[] \mathrm{Hz}$

- $100 \%$ load rejection []$\%[]$ Hz

- $50 \%$ load application []$\%[] \mathrm{Hz}$

- $50 \%$ load rejection []$\%[] \mathrm{Hz}$

q. Design life [] yrs

\section{B.2 UPS static switch data.}

a. Type

b. Transfer time

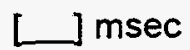

c. Duration of interruption of power to uninterruptible ac bus during transfer, if different from transfer time $\mathrm{msec}$

d. Short time current rating:

- Current

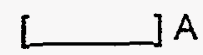

- Duration $\mathrm{msec}$

B.3 Maintenance bypass switch.
a. Type

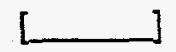
b. Ratings
c. Make-before-break type

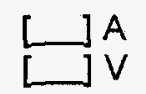
[Yes] [No] 


\section{B.4 Rectifier.}

a. Overload capacity at full voltage:

- For 30 seconds

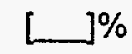

- For 25 milliseconds

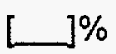

b. Time to recharge battery to $95 \%$ of

full capacity following a discharge

of full reserve time, while

supporting a fully-loaded inverter

B.5 Protective device types and ratings.

a. Normal input to system:

- Device

- Rating J

b. Bypass input to system:

- Device

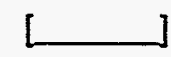

- Rating I

c. Output of system:

- Device

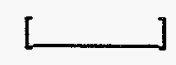

- Rating JA

d. Internal dc source:

- Device

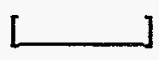

- Ratings

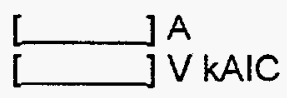

B.6 Mean time between failure (MTBF). The proposed UPS module has an MTBF of L (MTBF shall be calculated as MTBF UPS System/MTTR UPS System, where MTTR = mean time to repair.)

B.7 Seismic requirements. The UPS module proposed [does] [does not] meet the requirements outlined in paragraph 3.2 .4 of this specification. 
B.8 Sound requirements. The UPS module proposed [does] [does not] meet the requirements outlined in paragraph 3.4 of this specification.

B.9 Environmental considerations. The operating environment for this installation [will] [will not] affect the life expectancy of the components used in this equipment. If there will be an effect, the following components will be affected as listed below: 
DOE-SPEC-3021-97

INTENTIONALLY LEFT BLANK

B-6 


\section{APPENDIX C \\ GENERAL GUIDELINES FOR UPS SELECTION}

\section{GENERAL}

A UPS is, by definition, a system that maintains continuity of electric supply to critical loads for a specified period of time upon loss of primary ac input power. Many different types of UPS configurations are available, but this document defines the simplest configuration, which is called a "Single UPS Unit" (see NEMA PE 1).

The single UPS unit used as a base system for the guide specification is typical for most applications. There are two other types of systems that use step-wave inverters, or are rotational (motor-generator) systems that will have differences in some parts of the specification.

\section{UPS SYSTEM DESCRIPTION}

The typical UPS system is shown in block diagram form in figure 1. Note that the UPS system to be provided by Seller includes a battery system that will dictate the stored energy time available. The battery provided by the Seller must be specified using either DOE Standard "Sealed Valve-Regulated Type Lead-Acid Storage Batteries" or "Flooded-Type Lead-Acid Storage Batteries."

It should also be noted that the overall system is designed for dual ac input sources; a normal source which feeds the input of the rectifier charger, and a bypass source which is routed to the critical load via either the static transfer switch or the maintenance bypass switch. These two input sources are usually derived from either a common or two separate commercial power sources. If the bypass source voltage does not match the output voltage of the UPS inverter, it will be necessary to use a transformer in the bypass feed. This transformer can usually be supplied by the UPS manufacturer and should be specified if required.

A standby generator may be used as an alternate input source, should the load reliability requirement dictate the need for it. If a standby generator is used as an alternate input source, it would automatically be selected when commercial power is lost. The selection of the input source and how it should be connected to the UPS inputs is the facility engineer's responsibility.

The following building blocks make up the typical single unit UPS system:

Isolation Transformer

Input Filter
Attenuates the passage of noise or transients from its primary winding into its secondary winding.

Attenuates the effects of high-order harmonics and transients generated by the UPS and keeps them from feeding back into the input power source. 
Rectifierl Charger

Inverter

Static Transfer Switch

Maintenance Bypass

Switch

Internal Maintenance

Bypass Switch

Storage Battery

Battery Safety Disconnect Switch

Output Filter
Converts ac input power to dc output power for charging the storage battery and provides power to the inverter input.

Converts the $d c$ input power to a regulated and filtered ac output power which is supplied to the critical load.

Automatically transfers the critical loads, without interruption, from the inverter output to the internal bypass power source in the event of an inverter problem. Also referred to as the internal bypass switch.

Connects the maintenance bypass power source to the critical loads while electrically isolating the static switch and inverter for maintenance purposes. This should be a make-before-break type switch.

Connects the normal power source to the critical loads through the static transfer switch while electrically isolating the rectifier and inverter for maintenance.

The stored energy source which provides dc power to the inverter input when the normal ac power to the UPS module fails or in the event of rectifier/charger failure.

Connects the storage battery to the rectifier. The disconnect switch isolates the storage battery from the UPS module for maintenance and personnel safety.

Blocks high frequencies or steep wavefront transients generated by the UPS or load from feeding back into the load or UPS, respectively. 
DOE-SPEC-3021-97

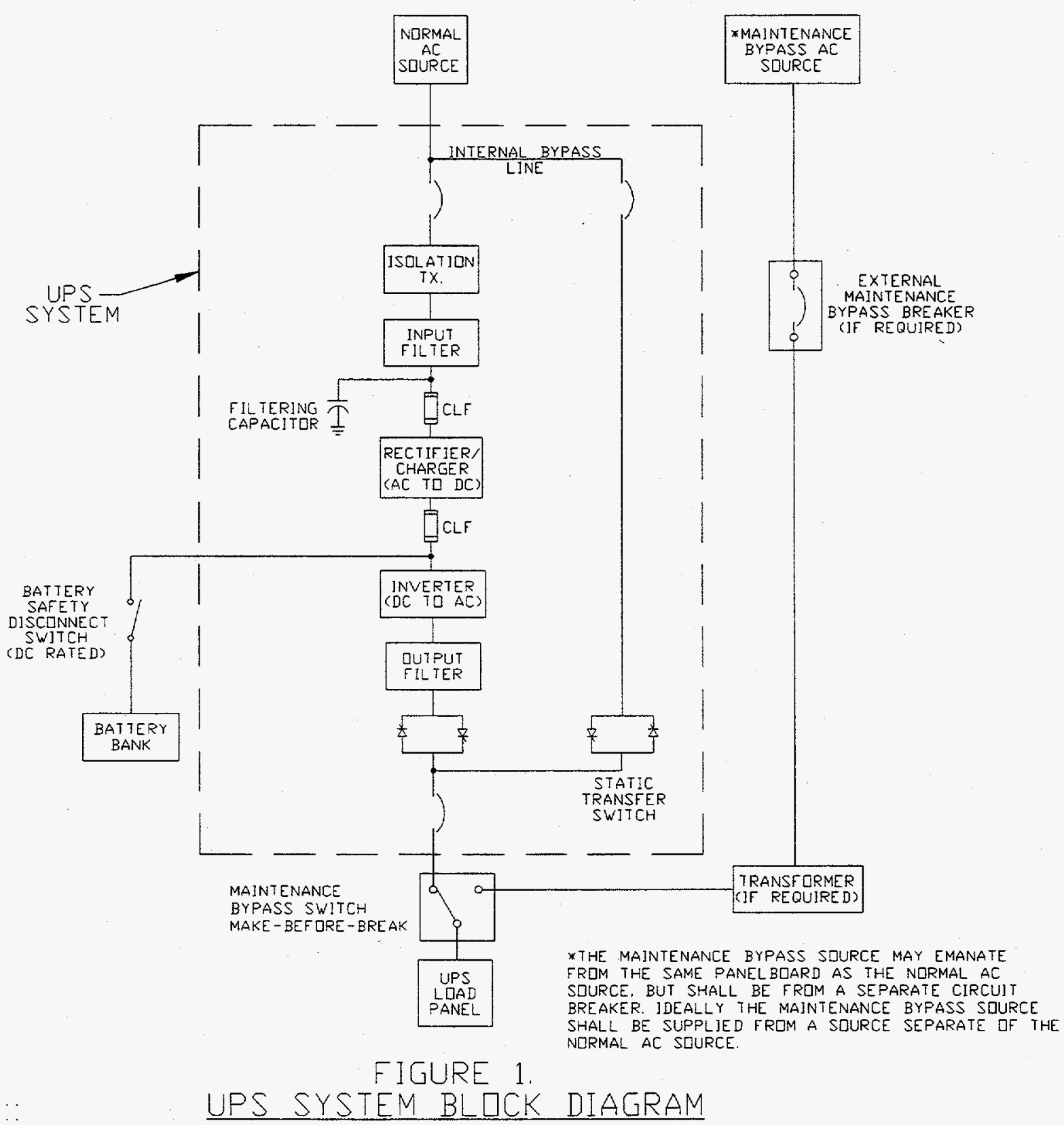




\section{SPECIFIER'S CHECKLIST}

This section contains a checklist for the specifier to use in organizing technical material prior to using the "fill-in-the-blanks" guide specification. It is recommended that the checklist be prepared before tackling the specification, but the guide specification is fully self-contained and may be used without the checklist if the specifier so desires.

This checklist is the list of paragraphs in the guide specification that require input from the specifier. The list may therefore be used to ensure that all the necessary input has been addressed and entered into the specification. The list may also be used as a study guide when consulting supplemental references.

\section{PARAGRAPH ACTION}

1.1

3.2 .6
Purpose. Supply the facility name and location, and the kVA rating of the UPS system.

Definitions. Supply appropriate definitions of "Owner" and "Seller" to avoid confusion.

Work to be Provided. Supply the specification number of the companion battery specification.

System Characteristics. Supply the base characteristics of the UPS system, including output characteristics, system effeciency, etc.

Design Life. Supply the expected design life of the system.

MTBF. Supply the expected mean time between failure (MTBF) of the system.

Normal Input Sources. Supply the characteristics of the normal input source.

Internal Bypass Source. Supply the characteristics of the bypass source input.

UPS Module Output. Supply the characteristics of the inverter output.

Seismic Requirements. Supply the seismic zone coefficient value (Z).

Operating Environment. Supply the characteristics of the operating environment.

Conformance with Existing Cables. Supply data concerning existing facility cables. 
3.3.2.1

3.3.2.2

3.3.2.3

3.3.2.4

3.3.2.6. $b$
Output Voltage. Supply data concerning acceptable inverter output voltage.

Transient Response. Supply UPS transient response characteristics.

Harmonic Content. Supply the allowable harmonic content of the inverter output.

Inrush. Supply the expected inrush.

Synchronization. Supply the frequency and phase differences on which synchonization will be based.

Controls. Supply rectifier/charger control variables.

Type. Supply the rectifier pulse type.

Battery Power Supply. Supply the characteristics of the battery power supply.

Static Transfer Switch. Supply conditions under which the transfer switch will transfer from the inverter output to the bypass source.

Retransfer. Indicate whether or not the transfer switch will retransfer on restoration of normal conditions.

Inrush. Indicate the maximum inrush the transfer switch can tolerate.

Transfer Time. Indicate the maximum allowable transfer time.

Isolation Transformer. Indicate the characteristics of the isolation transformer.

Alarms. Indicate alarm preferences.

Wiring. This section may require custom markup if special conditions dictate. Review it carefully.

Panel-Mounted Items. Indicate if phase selection switches will be required.

Data Submission Schedule. Check this schedule and provide submission dates compatible with overall project dates. 
DOE-SPEC-3021-97

INTENTIONALLY LEFT BLANK

C-6 
DOE-SPEC-3021-97

\section{ATTACHMENT 1: SKETCHES}

\section{Sketch}

L

\section{ATTENTION:}

Prepare and attach a sketch or drawing for each room where the UPS will be installed. Existing conditions as well. as proposed layout may be included for clarity. Identify each sketch by number and show the following information:

- Room dimensions, including all required minimum clearances

- Location of doors and windows

- Location of other important components.

SKETCH [ ]: 
Title:

$\overline{\text { Approved } \quad[\ldots . . . . . . . . . . .]}$

UNINTERRUPTIBLE POWER

SUPPLY (UPS) SYSTEM

$10 \mathrm{KVA}$ AND LARGER

$\overline{\text { Checked } \quad[\ldots \ldots \ldots \ldots . . . .]}$

Originated

$[\ldots \ldots \ldots \ldots . . . .$.

\section{CONTENTS}

1.0 SCOPE ...... 1

2.0 APPLICABLE DOCUMENTS 2

3.0 REQUIREMENTS 3

4.0 DOCUMENTATION 14

5.0 QUALITY ASSURANCE 16

6.0 INSPECTION AND TESTING 17

7.0 PREPARATION FOR DELIVERY 18

\section{APPENDIX A: ADDITIONAL TECHNICAL REQUIREMENTS}

APPENDIX B: UPS SYSTEM DATA SHEETS

\section{ATTACHMENT 1: SKETCHES}

\section{ATTENTION:}

This document was developed at Lawrence Livermore National Laboratory, which is managed by the University of California. Revise the format of this page for each site as appropriate. If the selected format is similar to this, insert the names of the originator (or author), approver (the originator's discipline chief), and the checker (At LLNL, the Standards \& Documentation Group editor.) The term "University" is used throughout; change to "Owner" or site-specific term for the purchaser. To facilitate record tracking, the LLNL S\&D Group assigns a unique "PPS" (Plant Procurement Specification) number to each specification, as noted in the header. 
DOE-SPEC-3021-97

CONCLUDING MATERIAL

Review Activities

\section{DOE HQ:}

$$
\text { DP }
$$

$\mathrm{EH}$

EH

EM

ER

FE

FM

HR

NE

RW

NN
Preparing Activity:

DP-45

Field Office:

Project Number:

Hanford

RF

Laboratories:

ANL

LANL

LLNL

SRS 


\begin{tabular}{|l|c|c|}
\hline $\begin{array}{l}\text { DOEF 1300.3 } \\
\text { (01-94) }\end{array}$ & $\begin{array}{c}\text { U.S. DEPARTMENT OF ENERGY } \\
\text { DOCUMENT IMPROVEMENT PROPOSAL } \\
\text { (Instructions on Reverse) }\end{array}$ & $\begin{array}{l}\text { OMB Control No. } \\
1910-0900 \\
\text { OMB Burden Disclosure } \\
\text { Statement on Reverse }\end{array}$ \\
\hline 1. Document Number & 2. Document Title & $\begin{array}{l}\text { 4. Type of Organization (Mark one) } \\
\square \text { Vendor } \\
\text { Uaser }\end{array}$ \\
\hline 3a. Name of Submitting Organization & $\begin{array}{c}\text { Manufacturer } \\
\square \text { Other (Specify: }\end{array}$ \\
\hline
\end{tabular}

5. Problem Areas (Attach extra sheets as needed.)

a. Paragraph Number and Wording

b. Recommended Wording

c. Reason/Rationale for Recommendation

6. Remarks

7a. Name of Submitter (Last, First, MI)

7b. Work Telephone Number (Include Area Code)

7c. Mailing Address (Street, City, State, Zip Code)

8. Date of Submission 
INSTRUCTIONS: In a continuing effort to improve the U.S. Department of Energy (DOE) Technical Standards, this form is provided for use in submitting comments and suggestions for improvements. All users of DOE Technical Standards are invited to provide suggestions. This form may be detached, folded along the lines indicated, taped along the loose edge (DO NOT STAPLE) mailed to the address indicated or faxed to (615) 574-0382.

1. The submitter of this form must complete blocks 1 through 8 .

2. The Technical Standards Program Office (TSPO) will forward this form to the Preparing Activity. The Preparing Activity will reply to the submitter within 30 calendar days of receipt from the TSPO.

NOTE: This form may not be used to request copies of documents, nor to request waivers, deviations, or clarification of specification requirements on current contractors. Comments submitted on this form do not constitute or imply authorization to waive any portion of the referenced document(s) or to amend contractual requirements.

\section{OMB Burden Disclosure Statement}

Public reporting burden for this collection of information is estimated to average 30 minutes per response, including the time for reviewing instructions, searching existing data sources, gathering and maintaining the data needed, and completing and reviewing the collection of information. Send comments regarding this burden estimate or any other aspect of this collection of information, including suggestions for reducing this burden, to Office of Information Resources Management Policy, Plans, and Oversight, Records Management Division, HR-422 - GTN, Paperwork Reduction Project (1910-0900), U.S. Department of Energy, 1000 independence Avenue, S.W., Washington, DC 20585; and to the Office of Management and Budget (OMB), Paperwork Reduction Project (1910-0900), Washington, DC 20503.

U.S. Department of Energy Technical Standards Program Office clo Performance Assurance Project Office

P.O. Box 2009, Bldg. 9201-3

Oak Ridge, Tennessee 37831-8065 